\title{
M-health-technologie: wat vindt de eerstelijnszorgverlener?
}

Eline Meijer

Digitale toepassingen in de zorg hebben een implementatiesprint getrokken met de komst van het coronavirus. Videoconsulten zijn ineens aan de orde van de dag. Maar $\mathrm{m}$-health (mobile health)-toepassingen waren eigenlijk al niet meer weg te denken uit het Nederlandse zorglandschap. Bekende voorbeelden zijn beslisondersteuning op een tablet, sms-herinneringen voor afspraken of monitoring van gezondheid van patiënten op afstand. Een cochranereview van kwalitatieve onderzoeken zocht uit hoe zorgverleners tegen $\mathrm{m}$-health-toepassingen aankijken. Geconcludeerd wordt dat $\mathrm{m}$-health geen one-size-fits-all oplossing is en er in iedere situatie moet worden bekeken wat er nodig is om $\mathrm{m}$-health-toepassingen zo goed mogelijk te laten functioneren.

Uit eerder kwantitatief onderzoek blijkt dat m-health (mobile health) soms werkt, en soms niet. De auteurs van een recente cochranereview hebben geprobeerd dit wisselende beeld te verklaren en gingen na in welke context $\mathrm{m}$-health-interventies worden aangeboden. Zij includeerden uitsluitend kwalitatieve onderzoeken. De auteurs concluderen dat m-health invloed heeft op de samenwerking tussen zorgverleners, de manier waarop de zorg wordt verleend, en de relatie tussen de zorgverlener en de patiënt. Deze veranderingen kunnen zowel positief als negatief zijn. Verschillende factoren zijn hierop van invloed, zoals de kosten, de zorgverlener zelf, de technologie en - vanuit een breder perspectief - het gezondheidszorgsysteem en de maatschappij.

De auteurs bundelden 43 kwalitatieve onderzoeken, voornamelijk uitgevoerd in laag- en middeninkomenslanden, om in kaart te brengen hoe eerstelijnszorgverleners m-health zien en ervaren. ${ }^{1}$ De m-health-toepassingen betroffen voornamelijk beslisondersteuning, communicatie via sms of beeld en registratie van gezondheidsinformatie van patiënten. In bijna de helft van de onderzoeken werd de m-health-toepassing gebruikt in de zorg voor moeders, kinderen en pasgeborenen. Uit de grondige synthese van resultaten komen maar liefst 40 bevindingen naar voren, waarvan we de belangrijkste hier kort bespreken.

Veel zorgverleners vinden het prettig dat ze met m-health meer verbonden zijn met elkaar en merken dat de coördinatie en kwaliteit van zorg erdoor verbetert. In sommige gevallen zorgt $\mathrm{m}$-health juist voor frustraties en miscommunicaties tussen collega's. M-health maakt ook dat zorgverleners nieuwe taken oppakken, flexibel kunnen werken en zorg kunnen verlenen aan patiënten in moeilijk bereikbare gebieden. Zorgverleners oordelen minder positief wanneer m-health-toepassingen langzaam of tijdrovend zijn, of extra werk opleveren.

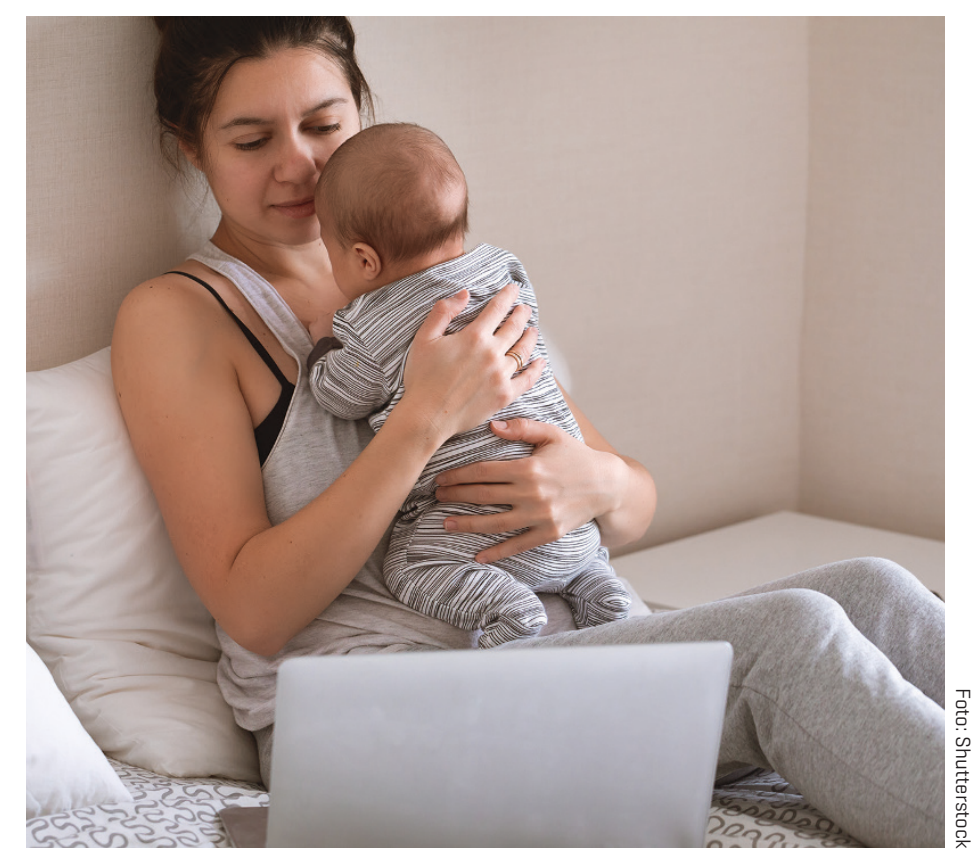

Sommige zorgverleners vinden beslissingsondersteuning via $\mathrm{m}$-health prettig, terwijl andere het ervaren als een bedreiging van hun klinische vaardigheden. Ook een deel van de patiënten is sceptisch over m-health en heeft een voorkeur voor face-to-face contact. Soms zijn er praktische problemen met de mobiele telefoon van de patiënt, zoals onvoldoende beltegoed, of ontbreekt elektriciteit. Zorgverleners merken dat andere patiënten $\mathrm{m}$-health juist prettig vinden en dat het gebruik ervan de relatie met deze patiënten verbetert. M-health maakt ook dat zorgverleners buiten de formele werktijden gemakkelijker contact hebben met patiënten. Een deel van de zorgverleners heeft hier geen moeite mee, terwijl andere hierin juist grenzen willen stellen.

De cochranereview beschrijft ook een breed scala aan factoren die van invloed zijn op percepties en het gebruik van $\mathrm{m}$-health door zorgverleners. Naast praktische aspecten, zoals kosten en technische problemen, blijkt dat sommige zorgverleners gemakkelijker met $m$-health uit de voeten kunnen dan andere. Zorgverleners die minder digitaal vaardig zijn schamen zich soms tegenover patiënten of maken zich zorgen over het behoud van hun baan. Factoren die het gebruik van $\mathrm{m}$-health bevorderen zijn training, technische ondersteuning, gebruiksvriendelijke apparaten en een goede integratie van $m$-health-toepassingen in bestaande systemen. De auteurs besluiten met een praktische handreiking voor een succesvolle toepassing van m-health. 


\section{COMMENTAAR}

Voor een deel kan deze cochranereview de heterogene uitkomsten van kwantitatief (effectiviteits)onderzoek verklaren. Het meeste kwantitatieve onderzoek (naar de effectiviteit van $\mathrm{m}$-health) is echter uitgevoerd in hooginkomenslanden, terwijl driekwart van de geïncludeerde kwalitatieve onderzoeken is uitgevoerd in laag- en middeninkomenslanden. ${ }^{2}$ Bij het wegen van de resultaten hebben de auteurs daarom gecorrigeerd voor de herkomst van de onderzoeken (GRADE). Een deel van de uitkomsten is wegens te grote verschillen in de organisatie van zorg niet generaliseerbaar naar de context van het Nederlandse zorgsysteem. Hoewel andere bevindingen voor ons op het eerste oog minder relevant lijken, zoals het belang van de beschikbaarheid van een telefoon of elektriciteit, spelen deze in Nederland wel degelijk een rol, bijvoorbeeld bij mensen met een lagere sociaaleconomische status (SES). Daarnaast is een deel van de bevolking niet voldoende digitaal vaardig om $\mathrm{m}$-health adequaat te kunnen gebruiken. Het risico bestaat dan ook dat $\mathrm{m}$-health-toepassingen de al bestaande gezondheidsverschillen tussen hogere en lagere SES vergroten. Daarom is het van belang om ook mensen met een lagere-SES-achtergrond en/of verminderde digitale vaardigheden te betrekken bij de ontwikkeling en implementatie van $\mathrm{m}$-health, zodat $\mathrm{m}$-health kan bijdragen aan een betere gezondheid voor iedereen.
M-health is dus geen one-size-fits-all oplossing en in iedere situatie moet worden bekeken wat er nodig is om deze toepassingen zo goed mogelijk te laten functioneren. Het praktische overzicht van implementatievragen uit de review is daarvoor zeer bruikbaar. -

\section{LITERATUUR}

1. Odendaal WA, Anstey Watkins J, Leon N, Goudge J, Griffiths F, Tomlinson M, et al. Health workers' perceptions and experiences of using mHealth technologies to deliver primary healthcare services: a qualitative evidence synthesis. Cochrane Database Syst Rev 2020;3:CD011942.

2. Marcolino MS, Oliveira JAQ, D’Agostino M, Ribeiro AL, Alkmim MBM, Novillo-Ortiz D. The impact of mHealth interventions: systematic review of systematic reviews. JMIR Mhealth Uhealth 2018;6:e23.

\section{NHG-Werkgroep Geschiedenis Huisartsgeneeskunde zoekt nieuwe leden}

\section{Huisartsen met belangstelling voor de geschiedenis van het vak kunnen hun hart ophalen bij de NHG-Werkgroep Geschiedenis Huisartsgeneeskunde. De werkgroep zoekt nieuwe leden.}

De werkgroep is in 2012 opgericht met als doel het bevorderen van historisch besef en kennis over de geschiedenis van de huisartsgeneeskunde en het vastleggen van de uitgangpunten en de geschiedenis van het vak. Een van de projecten van de werkgroep was het maken van een serie artikelen voor H\&W over de geschiedenis van de huisartsgeneeskunde en het uitbrengen van het gelijknamige boek. Een ander project was het maken van een handleiding voor het beheer van huisartsenarchieven.

Ook in de toekomst wil de werkgroep aanspreek- en informatiepunt/klankbord voor de geschiedenis van de huisartsgeneeskunde blijven. Met activiteiten als het verzorgen van voordrachten [onder meer in de huisartsopleiding], publicaties over de geschiedenis van de huisartsgeneeskunde en hulp bij archivering. De werkgroep werkt nauw samen met het Trefpunt Medische Geschiedenis in Urk.

BELANGSTELLING? Heb je belangstelling? Neem dan contact op met Ron Helsloot, secretaris van de werkgroep, r.helsloot@kpnplanet. nl of voorzitter Mely van Malenstein, mvanmalenstein@hetnet.nl.

http://nhgonline.nl/mijlpalen/huisartsarchieven 